\title{
Effects of Increased Iron Intake During the Neonatal Period on the Brain of Adult A $\beta$ PP/PS1 Transgenic Mice
}

\author{
Liana Lisboa Fernandez ${ }^{\mathrm{a}, \mathrm{b}, \mathrm{c}, *}$, Marga Carmona ${ }^{\mathrm{c}}$, Manuel Portero-Otin ${ }^{\mathrm{d}}$, Alba Naudi ${ }^{\mathrm{d}}$, \\ Reinald Pamplona ${ }^{\mathrm{d}}$, Nadja Schröder ${ }^{\mathrm{a}}$ and Isidro Ferrer ${ }^{\mathrm{c}}$ \\ ${ }^{a}$ Neurobiology and Developmental Biology Laboratory, Pontifical Catholic University, Porto Alegre, RS, Brazil \\ ${ }^{\mathrm{b}}$ Health Basic Science Department, Federal University of Medical Science, Porto Alegre, RS, Brazil \\ ${ }^{\mathrm{c}}$ Institut de Neuropatologia, Servei Anatomia Patològica, IDIBELL-Hospital Universitari de Bellvitge, Universitat \\ de Barcelona, Hospitalet de LLobregat, CIBERNED, Spain \\ ${ }^{\mathrm{d}}$ Department of Experimental Medicine, University of Lleida-IRBLLEIDA, Lleida, Spain
}

Handling Associate Editor: Sigfrido Scarpa

Accepted 9 October 2009

\begin{abstract}
The present study was aimed to investigate neuropathological changes in A $\beta$ PP/PS1 transgenic mice (Tg), as a model of Alzheimer's disease, subjected to supplementary iron administration in a critical postnatal period, in order to reveal the interaction of genetic and environmental risk factors in the pathogenesis of the disease. Twelve Tg and 10 wild-type (Wt) littermates were administered iron between the 12th and 14th post-natal days ( $\mathrm{TgFe}, \mathrm{WtFe}) ; 11 \mathrm{Tg}$ and $15 \mathrm{Wt}$ received vehicle (sorbitol 5\%) alone in the same period $(\mathrm{TgSb}, \mathrm{WtSb})$. Mice were killed at the age of six months and processed for morphological and biochemical studies. No modifications in amyloid- $\beta$ burden were seen in iron-treated and non-iron-treated A $\beta$ PP/PS1 mice. No differences in microglial reactions were observed when comparing the four groups of mice. Yet increased astrocytosis, as revealed by densitometry of GFAP-immunoreactive astrocytes, and increased expression levels of GFAP, as revealed by gel electrophoresis and western blotting, were found in iron-treated mice (both $\mathrm{Tg}$ and $\mathrm{Wt}$ ) when compared with $\mathrm{TgSb}$ and $\mathrm{WtSb}$. This was accompanied by significant changes in brain fatty acid composition in A $\beta$ PP/PS1 mice that led to a lower membrane peroxidizability index and to reduced protein oxidative damage, as revealed by reduced percentages of the oxidative stress markers: glutamic semialdehyde, aminoadipic semialdehyde, $\mathrm{N}^{\varepsilon}$-carboxymethyl-lysine, $\mathrm{N}^{\varepsilon}$-carboxyethyl-lysine, and $\mathrm{N}^{\varepsilon}$-malondialdehyde-lysine. These findings demonstrate that transient dietary iron supplementation during the neonatal period is associated with cellular and metabolic imprinting in the brain in adult life, but it does not interfere with the appearance of amyloid plaques in $\mathrm{A} \beta \mathrm{PP} / \mathrm{PS} 1$ transgenic mice.
\end{abstract}

Keywords: A $\beta$ PP/PS1 transgenic mice, Alzheimer's disease, docosahexaenoic acid, docosapentaenoic acid, GFAP, iron, neurodegeneration, peroxidizability index, protein oxidation

\section{INTRODUCTION}

* Correspondence to: Liana Lisboa Fernandez, Rua Coronel Bordini, 675, sala 204, Porto Alegre, CEP 90440-001, RS, Brasil. Tel.: +55 51 33325983; E-mail: llfernandez@ plugin.com.br.
The number of elderly has risen with the increase of life expectancy and, as a consequence, the prevalence of age-related diseases including neurodegenerative disorders has increased as well [1]. Neuropathological changes in many degenerative diseases of the nervous system are characterized by the presence of abnormal 
proteins which accumulate in the brain, leading to a selective loss of neurons in an age-dependent manner [13]. Alzheimer's disease (AD) is the leading cause of dementia in the elderly $[1,2,4]$. AD is a multisystemic disease involving the neuronal circuits in the entorhinal and perirhinal cortex, hippocampal complex, amygdala, and neocortex, together with the basal forebrain cholinergic system, striatum, thalamus, and several nuclei of the brain stem. The neuropathological hallmarks of $\mathrm{AD}$ are extracellular deposits of amyloid- $\beta$ peptides $(\mathrm{A} \beta)$ consisting of diffuse or neuritic plaques, and amyloid angiopathy; and intraneuronal deposits of hyperphosphorylated tau manifested as neurofibrillary pre-tangles and tangles, dystrophic neurites of neuritic plaques, and neuropil threads [1-4]. Sporadic AD is a common multifactor complex disorder resulting from the interaction of both genetic (e.g., APOE) and environmental factors in aged individuals [4-6]. Familial $\mathrm{AD}$ is a very rare autosomal dominant disease, often with early onset, caused by mutations in the amyloid- $\beta$ protein precursor and presenilin genes $(A \beta P P, P S E N 1$, PSEN2) both linked to A $\beta$ metabolism [3-5].

Several transgenic animal models have been produced to recapitulate particular aspects of $\mathrm{AD} . \mathrm{A} \beta \mathrm{PP} /$ PS1 transgenic mice overexpress both mutant human $\mathrm{A} \beta \mathrm{PP}$ and PS 1 and show early and extensive $\mathrm{A} \beta$ deposition in the form of plaques and amyloid angiopathy [7-9]. A $\beta$ PP/PS1 transgenic mice show progressive amyloid plaque formation, dendritic spine loss, astrocytosis, and behavioral deficiencies [10-13].

Increasing evidence shows that, in spite of vital physiological functions, iron may play a role in metal-ionmediated oxidative damage under certain conditions, most clearly pronounced with aging [14-20]. Accumulation of proteins related with iron storage as ferritin and hemosiderin occurs in the hippocampus, and probably other regions, in AD [21]. However, regions undergoing degeneration display an excess of iron relative to ferritin levels which may indicate that iron accumulates at a faster rate than ferritin is produced [22]. Moreover, iron-activated $\mathrm{A} \beta$ and plaque formation induces activation of microglia and reactive astrocytosis [22]. Furthermore, iron co-localizes with $\mathrm{A} \beta$ in amyloid plaques in $\mathrm{A} \beta \mathrm{PP} / \mathrm{PS} 1$ transgenic mice [23].

Several studies have shown that neonatal iron exposure may induce neurobehavioral and cognitive dysfunctions in adult mice [24,25]. Similar deficits are observed in adult rats after postnatal iron administration [26-30]. These effects are reversed by selegiline [30] and the iron chelator desferoxamine [28]. In these models, iron is given orally during the period of maximal iron uptake by the brain so that the rodent models mimic dietary iron supplementation to human infants [28].

The present study was designed to investigate histological and biochemical modifications in adult $\mathrm{A} \beta \mathrm{PP} / \mathrm{PS} 1$ transgenic mice subjected to transient iron administration at a critical postnatal period. The main objective was to evaluate the interaction of genetic and environmental factors in the pathology of the disease.

\section{MATERIAL AND METHODS}

\section{Animal treatment}

Twenty three 6-month-old A $\beta$ PP/PS1 transgenic mice (Tg) from the Jackson Laboratory (Bar Harbor, Maine, USA) and 25 age-matched littermate control mice $(\mathrm{Wt})$ were used. The mouse line used in this study expressed a $\mathrm{Mo} / \mathrm{Hu} \mathrm{A} \beta \mathrm{PP} 695$ swe construct in conjunction with the exon-9-deleted variant of human presenilin 1 (PS1-dE9) [8]. Details of neuropathological and behavioral aspects of these mice are reported elsewhere $[11,13]$.

Twelve $\mathrm{Tg}$ and $10 \mathrm{Wt}$ were subjected to iron administration between the 12th and the 14th postnatal days $(\mathrm{TgFe}, \mathrm{WtFe}) ; 11 \mathrm{Tg}$ and $15 \mathrm{Wt}$ received vehicle alone during the same period ( $\mathrm{TgSb}, \mathrm{WtSb})$. The neonatal iron treatment was performed as previously described [24-30]. Briefly, 12-day-old mouse pups received a single oral daily dose $(10.0 \mathrm{ml} / \mathrm{kg}$ solution volume) of vehicle (5\% sorbitol in water) (control group) or $10.0 \mathrm{mg} / \mathrm{kg}$ of body weight of iron carbonyl (Sigma; iron concentration in the solution was $1.0 \mathrm{mg} / \mathrm{ml}$ ) via a metallic gastric tube for 3 days. All the process was conducted with the approval of the Committee for Animal Care and Research of the Autonomous Government of Catalunya.

\section{Immunohistochemical analyses $(I H Q)$}

Three TgFe, $3 \mathrm{TgSb}, 4 \mathrm{WtFe}$, and $4 \mathrm{WtSb}$ 6-month old mice were perfused through the left cardiac ventricle for 20 min with $4 \%$ paraformaldehyde in phosphate buffer. The brains were rapidly removed and immersed in the same fixative solution at room temperature. Immediately afterwards, the brains were cut sagitally and embedded in paraffin. Serial, 5 - $\mu$ m-thick coronal sections were obtained with a microtome and used for immunohistochemistry. De-waxed sections were immersed in $3 \%$ hydrogen peroxide in $100 \%$ methanol 
for $15 \mathrm{~min}$ to inhibit endogenous peroxidase activity. Then the sections were boiled in $10 \mathrm{mM}$ citrate buffer, $\mathrm{pH} 6.0$, for $30 \mathrm{~min}$ or treated with formic acid for $3 \mathrm{~min}$, for antigen retrieval. After rinsing in phosphatebuffered saline (PBS), the sections were incubated with normal horse serum for $2 \mathrm{~h}$ and then with the primary antibody overnight at $4{ }^{\circ} \mathrm{C}$ in humid chambers. The following primary antibodies were used: anti-A $\beta$ (monoclonal mouse anti-human A $\beta$, Dako, Barcelona, Spain), dilution 1:25, pretreated for 3 min with formic acid; anti-GFAP (monoclonal mouse anti-human glial fibrillary acidic protein, DAKOCYTOMATION), dilution 1:250, pretreated for $20 \mathrm{~min}$ with boiling citrate; and anti-lectin of Lycopersicon esculentum (L-0651, Sigma, Madrid, Spain), dilution 1:100, with no pretreatment.

The sections were washed three times in PBS and immunostained by a standard avidin-biotin complex method (secondary biotinylated universal Dako and Streptavidin HRP, Dako), washed and finally treated for 3 min with $0.01 \% \mathrm{H}_{2} \mathrm{O}_{2}$ and $0.05 \%$ diaminobenzidine tetrahydrochloride (DAB, Sigma) for optical detection, except for lectin, in which the sections were treated only with streptavidin and DAB.

\section{Western blot analysis}

Nine TgFe, 8 TgSb, $6 \mathrm{WtFe}$, and $11 \mathrm{WtSb}$ 6-monthold mice were killed by rapid decapitation and all brains were separated in regions and frozen in $-80^{\circ} \mathrm{C}$. Samples of the posterior hemisphere (including the hippocampus) of all animals were homogenized in a glass homogenizer in $600 \mu \mathrm{l}$ of RIPA buffer $(25 \mathrm{mM}$ Tris, $\mathrm{HCl} \mathrm{pH} 7.6,150 \mathrm{mM} \mathrm{NaCl}, 1 \% \mathrm{NP}-40,1 \%$ sodium deoxyenolate, $0.1 \%$ SDS) with phosphatase inhibitors (complex mini-protease inhibitors 1:10 ml, $\mathrm{NaV} 200 \mathrm{mM}$, NaF 1M, PMSF 10 0mM) and centrifuged at $10,000 \mathrm{rpm}$ for $5 \mathrm{~min}$ at $4^{\circ} \mathrm{C}$. Pellet fractions were discarded and protein concentrations of the supernatants were determined with the BCA method with bovine serum albumin as a standard. Samples containing $20 \mu \mathrm{g}$ of protein were loaded onto $10 \%$ acrylamide gels. Proteins were separated by sodium dodecyl sulfate (SDS)-polyacrylamide gel electrophoresis (PAGE) and electrophoretically transferred to nitrocellulose membranes ( $400 \mathrm{~mA}$ for $90 \mathrm{~min}$ ). Then the membranes were incubated with 5\% skimmed milk in TBS-T buffer (100 mM Tris-buffered saline, $140 \mathrm{mM} \mathrm{NaCl}$ and $0.1 \%$ Tween 20, $\mathrm{pH} 7.4$ ) for $1 \mathrm{~h}$ at room temperature, and incubated in primary antibody anti-GFAP (monoclonal mouse anti-human glial fibrillary acidic protein) di- luted 1:3,000 in TBS-T containing 3\% BSA (Sigma) overnight at $4^{\circ} \mathrm{C}$. Subsequently, the membranes were incubated with the secondary antibody (anti-rabbit) labeled with horseradish peroxidase (Dako) in a dilution of 1:1,000. Finally, membranes were developed with the chemiluminescence ECL Western blotting system (Amersham/Pharmacia, Barcelona, Spain) followed by apposition of the membranes to autoradiographic films (Hyperfilm ECL, Amersham). The monoclonal antibody to $\beta$-actin (Sigma) was used at a dilution of $1: 5,000$ as a control of protein loading.

\section{Densitometry and statistical processing of data}

The immunohistochemical images were captured using AxisVision AC Real 4.5 program, an inverted microscope with a 20x objective, and an AxioCam IC Zeiss camera. The selection was made manually including hippocampus or adjacent temporal cortex. To analyze the image the Image $J$ software was used (http://www.uhnresearch.ca/facilities/wcif/fdownload. html). For each image, color functions and color deconvolution, H DAB vectors: color 2 R: 0.26814753, G: 0.57031375 , B: 0.77642715 were applied. The color 2 image (brown) was inverted and the measurement was obtained as a percentage of the DAB chromogen. Data were expressed as mean \pm standard error of the mean (SEM). Comparisons between groups were performed using the independent samples T-TEST. $p$ values of less than 0.05 were considered statistically significant and these are indicated in the figure as $* p<$ 0.05 and $* * p<0.01$.

Western blotting analysis was performed by measuring protein levels using densitometry of all bands, measured with Total Lab v2.01 software. The results were normalized with $\beta$-actin. Data were expressed as mean \pm SEM. Comparisons among groups were performed with a one-way analysis of variance (ANOVA) followed by Tukey post-hoc test. $p$ values of less than 0.05 were considered statistically significant and these are indicated in the figure as $* p<0.05$ and $* * p<$ 0.01 .

\section{Mass spectrometry analysis of protein oxidative damage markers}

The same animals used for gel electrophoresis and western blotting were utilized for the study of brain lipid composition and oxidative stress markers (4 TgFe, $4 \mathrm{TgSb})$. The frontal and part of the parietal cortex were used for study. 
The markers of protein oxidation - the protein carbonyls glutamic (GSA) and aminoadipic (AASA) semialdehydes, glycoxidation (carboxyethyl-lysine CEL, and carboxymethyl-lysine CML), and lipoxidation (malondialdehydelysine MDAL, and CML) - were determined by gas chromatography/mass spectrometry (GC/MS). The trifluoroacetic acid methyl ester derivatives of these five markers were measured in acid hydrolyzed de-lipidated and reduced protein samples using an isotope dilution method as previously described [31], with an HP6890 Series II gas chromatograph (Agilent, Barcelona, Spain), an MSD5973A Series and a 7683 Series automatic injector, an HP5MS column (30-m x $0.25-\mathrm{mm} \times 0.25-\mu \mathrm{m})$, and the described temperature program [31]. Quantification was performed by external standardization using standard curves constructed from mixtures of deuterated and non-deuterated standards. Analyses were carried out by selected ion-monitoring GC/MS (SIM-GC/MS). The ions used were lysine and $\left[{ }^{2} \mathrm{H}_{8}\right]$ lysine, $\mathrm{m} / \mathrm{z}$ 180 and 187, respectively; 5-hydroxy-2-aminovaleric acid and $\left[{ }^{2} \mathrm{H}_{5}\right] 5$-hydroxy-2-aminovaleric acid (stable derivatives of GSA), $m / z 280$ and 285 , respectively; 6-hydroxy-2-aminocaproic acid and $\left[{ }^{2} \mathrm{H}_{4}\right] 6$-hydroxy2-aminocaproic acid (stable derivatives of AASA), $m / z 294$ and 298, respectively; CML and $\left[{ }^{2} \mathrm{H}_{4}\right] \mathrm{CML}$, $m / z 392$ and 396, respectively; CEL and $\left[{ }^{2} \mathrm{H}_{4}\right] \mathrm{CEL}$, $m / z 379$ and 383, respectively; and MDAL and [ ${ }^{2} \mathrm{H}_{8}$ ]MDAL, $m / z 474$ and 482 , respectively. The amounts of product were expressed as the $\mu$ molar ratio of GSA, AASA, CML, CEL, or MDAL/mol lysine.

\section{Fatty acid analysis}

Fatty acyl groups of brain lipids were analyzed as methyl ester derivatives by GC/MS as previously described [31]. Separation was performed in an SP2330 capillary column $(30 \mathrm{~m} \times 0.25 \mathrm{~mm} \times 0.20 \mu \mathrm{m})$ in a GC Hewlett Packard 6890 Series II gas chromatograph (Agilent). A Hewlett Packard 5973A mass spectrometer was used as detector in the electron-impact mode. Identification of fatty acyl methyl esters was made by comparison with authentic standards and on the basis of mass spectra. Results are expressed as mol\%. The following fatty acyl indexes were also calculated: saturated fatty acids (SFA); unsaturated fatty acids (UFA); monounsaturated fatty acids (MUFA); polyunsaturated fatty acids from n-3 and n-6 series (PUFAn-3 and PUFAn-6); average chain length $($ ACL $)=\left[\left(\sum \%\right.\right.$ Total 14 $\times 14)+(\Sigma \%$ Total16 $\times 16)+(\Sigma \%$ Total $18 \times 18)+$ $(\Sigma \%$ Total $20 \times 20)+(\Sigma \%$ Total $22 \times 22)] / 100] ;$ double bond index $(\mathrm{DBI})=[(1 \times \Sigma \mathrm{mol} \%$ monoenoic $)+(2$ x $\Sigma$ mol\% dienoic $)+(3 \times \Sigma$ mol\% trienoic $)+(4 \times$ $\Sigma$ mol\% tetraenoic $)+(5 \times \Sigma$ mol\% pentaenoic $)+(6 \times$ $\Sigma$ mol\% hexaenoic)], and peroxidizability index $(\mathrm{PI})=$ $[(0.025 \times \Sigma \mathrm{mol} \%$ monoenoic $)+(1 \times \Sigma$ mol\% dienoic $)$ $+(2 \times \Sigma \mathrm{mol} \%$ trienoic $)+(4 \times \Sigma$ mol\% tetraenoic $)+$ $(6 \times \Sigma$ mol\% pentaenoic $)+(8 \times \Sigma$ mol\% hexaenoic $)]$.

\section{Statistical analyses}

All values were expressed as means \pm SEM. Comparisons between experimental groups were statistically analyzed with Student's $t$ tests. The minimum level of statistical significance was set at $p<0.05$ in all the mass spectrometry analyses.

\section{RESULTS}

\section{Immunohistochemistry}

$\mathrm{A} \beta \mathrm{PP} / \mathrm{PS} 1$ mice treated neonatally either with iron or vehicle and killed at six months presented $\mathrm{A} \beta$ plaques in hippocampus (Fig. 1 a1, b1) and temporal cortex (Fig. 1 a2, b2). A $\beta$ plaques were not observed in the hippocampus (Fig. $1 \mathrm{c} 1, \mathrm{~d} 1$ ) and temporal cortex (Fig. 1 c2, d2) in Wt mice irrespectively of neonatal treatments. No significant differences in the number of plaques were seen in $\mathrm{Tg}$ mice treated with iron when compared with $\mathrm{Tg}$ mice treated with vehicle alone (data not shown).

In order to investigate the possibility of an inflammatory reaction in the tissue, labeling of microglia cells using lectin showed no differences between both $\mathrm{Wt}$ and Tg mice groups at six months of age treated with iron or sorbitol in the neonatal period.

In contrast, statistical analysis of densitometric immunohistochemistry for GFAP showed an increase in GFAP levels in the hippocampus $(p<0.05)$, but not in temporal cortex, in Wt mice that received iron in comparison to the group treated with vehicle alone in the neonatal period (Fig. 2). Moreover, GFAP levels were also significantly increased in the temporal cortex of A $\beta$ PP/PS1 mice treated with iron in comparison to the Tg group treated with vehicle alone $(p<0.05)$ (Fig. 3).

\section{Western blotting}

In order to confirm immunohistochemical findings, gel electrophoresis, and western blotting of total homogenates including the parietal cortex and hippocam- 

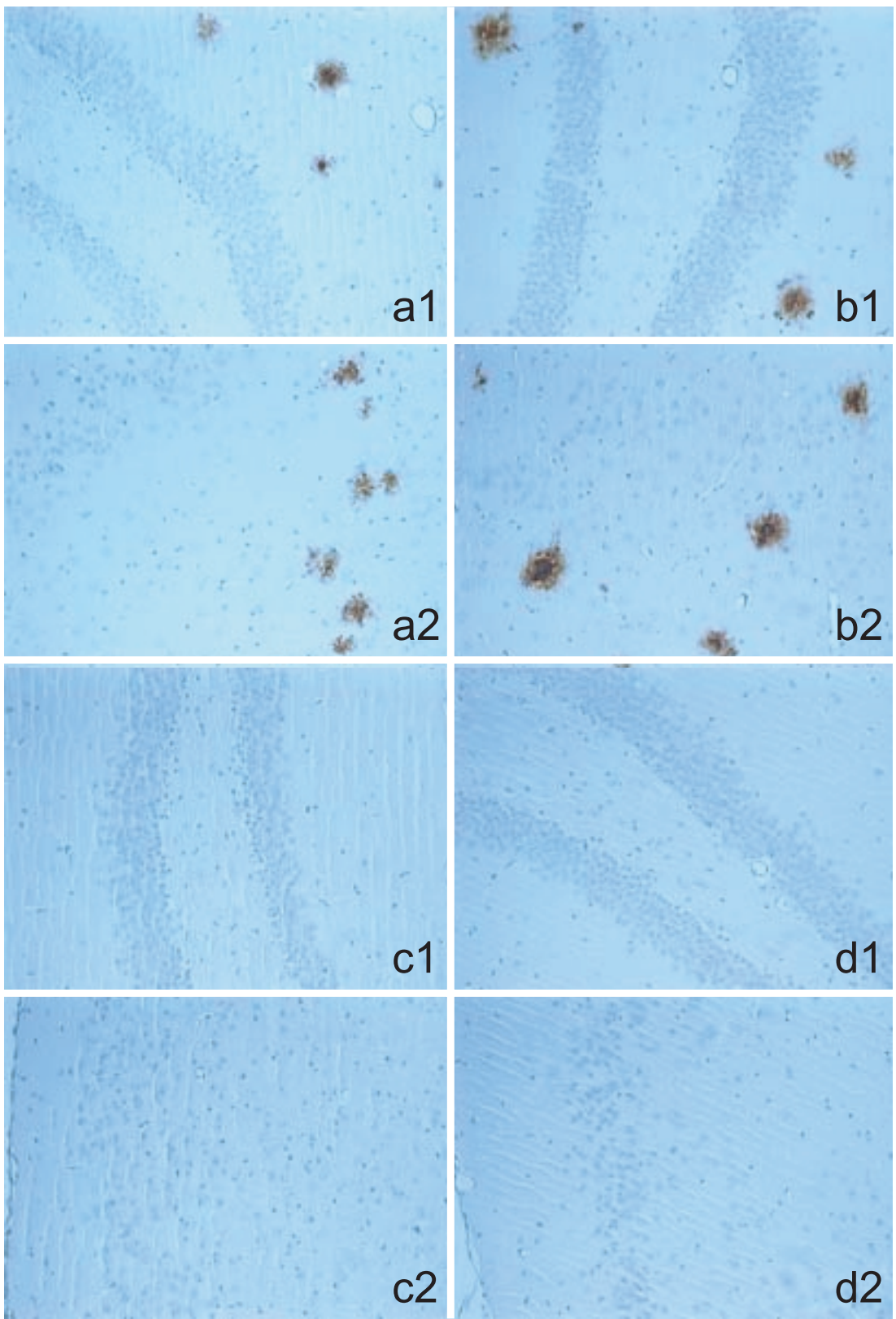

Fig. 1. Representative histological sections of $\mathrm{A} \beta$ immunohistochemistry of hippocampus (1) and temporal cortex (2) of (a) TgFe group; (b) $\mathrm{TgSb}$ group; (c) WtFe group; (d) WtSb group show amyloid plaques. Magnification: 20x. No differences among groups are observed.

pus was carried in Tg and Wt mice. Statistical comparison of GFAP band optic density normalized with $\beta$-actin showed significant differences among the different groups. Tukey post hoc test revealed that iron treatment in the neonatal period produced an increase in GFAP expression levels in Wt mice when compared with Wt mice treated with sorbitol alone $(p<0.01)$. Increased GFAP expression was seen in Tg mice when compared with Wt independently of neonatal iron exposure $(p<0.01)$ (Fig. 4). Expression levels of GFAP in $\mathrm{Tg}$ mice at six months treated with iron where higher, although not significantly so, when compared with mice treated with sorbitol alone.

\section{Fatty acid composition}

Table 1 shows the fatty acid composition of brain lip- 


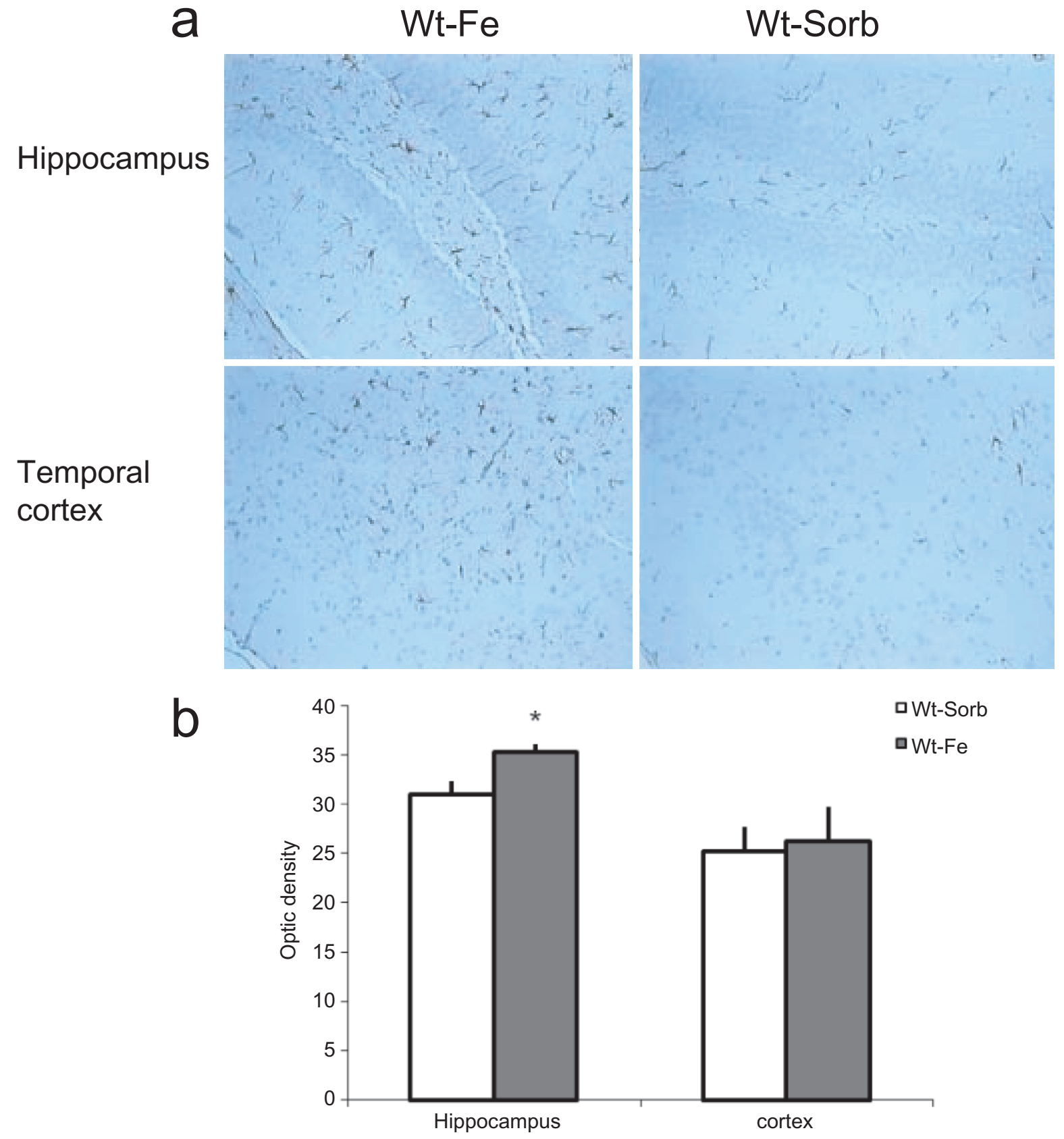

Fig. 2. Representative histological sections of GFAP immunohistochemistry of the hippocampus and temporal cortex of WtFe and WtSb groups show immunostained astrocytes. Magnification: 20x (a). Statistical analysis reveals a significant increase in GFAP in the hippocampus of Wt animals that received iron $(* p<0.05$, independent samples t-test) (b).

ids from both untreated and transeated $\mathrm{A} \beta \mathrm{PP} / \mathrm{PSIt}$ transgenic mice. Iron administration altered the fatty acid composition of total brain lipids, so that the total number of double bonds (DBI) and peroxidizability index (PI) was significantly decreased $(p<0.02$ and $p<$
0.02 , respectively). The fatty acids mainly responsible for the decrease in DBI and PI were basically from the PUFA n-3 series. Thus, iron transiently administered at neonatal period significantly increased, at the age of six months, the levels of saturated fatty acids such as 


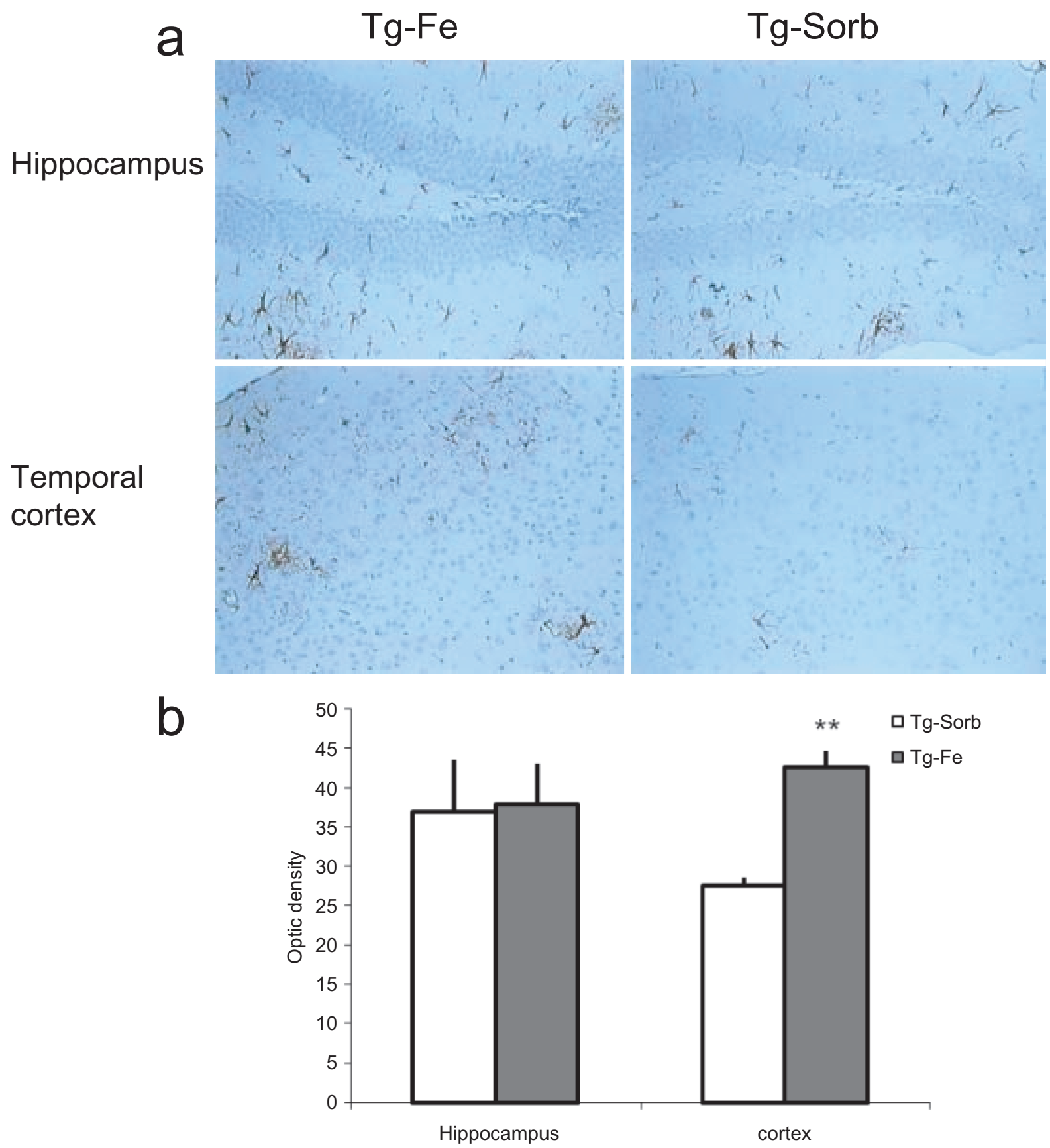

Fig. 3. Representative histological sections of GFAP immunohistochemistry of the hippocampus and temporal cortex of TgFe and TgSb groups show immunostained astrocytes. Magnification: 20x (a). A significant increase in GFAP is observed in the temporal cortex of transgenic animals that received iron $(* * p<0.01$, independent samples t-test) (b).

16:0 $(p<0.03)$ and 18:0 $(p=0.05)$, whilst it decreased the highly unsaturated eicosapentaenoic acid (20:5n-3) and docosapentaenoic acids (22:5n-3). The content of the highly unsaturated arachidonic acid (20:4n-6) and docosahexaenoic acid (22:6n-3) maintained stable. No changes were detected for monounsaturated fatty acids and PUFA n-6 contents. The membrane acyl composition indicated that the membranes maintained a similar, even though slightly lower, fatty acid average chain length (around 18 carbon atoms) in the $\mathrm{Tg}$-Fe group 


\section{GFAP 50kDa $=$}

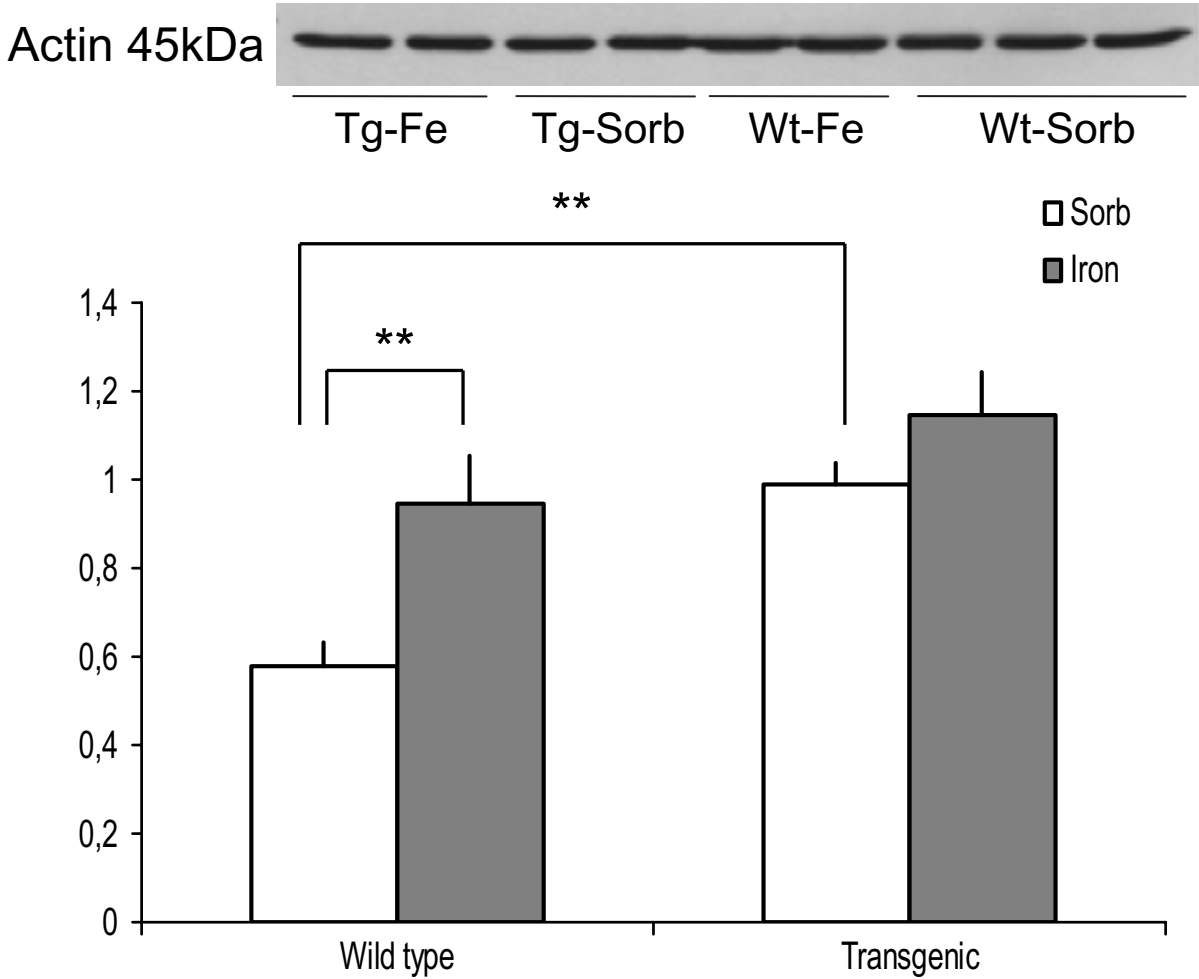

Fig. 4. Western blot analysis of GFAP in 1: WtSb $(n=11)$; 2: WtFe $(n=6) ; 3: \operatorname{TgSb}(n=8)$; and 4: $\operatorname{TgFe}(n=9)$. Increased expression levels of GFAP are seen in $\mathrm{WtFe}$ group versus $\mathrm{WtSb}$, and in $\mathrm{TgSb}$ group versus $\mathrm{WtSb} ; * * p<0.001$.

when compared with the group treated with sorbitol alone.

\section{Oxidative stress markers}

Concerning the steady-state level of the protein oxidative damage markers, the concentrations of all the five different oxidative (the specific protein carbonyls GSA and AASA), glycoxidative (CEL and CML) and lipoxidative (CML and MDAL) markers analyzed were significantly decreased by iron treatment in the $\mathrm{Tg}$ animal group (Table 2). The mean magnitude of all these decreases taken together was $23.0 \%$ in the brain of the $\mathrm{Tg}$ treated with iron when compared with the group treated with sorbitol alone.

\section{DISCUSSION}

The present findings have shown that transient iron intake during neonatal period induces astrocytic gliosis in $\mathrm{A} \beta \mathrm{PP} / \mathrm{PS} 1$ transgenic mice and in age-matched littermates at the age of six months, and that this change is not accompanied by apparent differences in microglial reactions and, more particularly, in $\mathrm{A} \beta$ burden, as revealed by the amount of $\mathrm{A} \beta$ plaques, in $\mathrm{A} \beta \mathrm{PP} / \mathrm{PS} 1$ transgenic mice at least, within the range of the period studied. With minor differences, GFAP changes are consistent with densitometry in GFAP immunostained sections and gel electrophoresis and western blotting. Administration of iron at very early stages of development resulting in very similar effects in $\mathrm{A} / \mathrm{PP} / \mathrm{PS} 1$ and age-matched littermates points to the fact that $\mathrm{A} \beta$ metabolism has no role in iron removal and later astrocytic responses in the neonatal period, in contrast to the well-known interactions of $\mathrm{A} \beta$ and iron in older individuals [32]. Similarly, the lack of differences regarding microglia does not give support to the concept that soluble $\mathrm{A} \beta$-metal complex may stimulate inflammatory responses and thereby promote rapid phagocytosis of the peptide [33]. 
Table 1

Fatty acyl composition (\%) of total lipids in the frontal cortex of A $\beta$ PP/PS1 transgenic mice treated with sorbitol (Tg sorbitol) or with iron $(\mathrm{TgFe})$ during the neonatal period and killed at six months of age. Values are means \pm SEM from $n=4$ samples. ACL: average chain length; SFA: saturated fatty acids; UFA: unsaturated fatty acids; MUFA: monounsaturated fatty acids; PUFAn $=3$ : polyunsaturated n-3 fatty acids; PUFAn-6: polyunsaturated n-6 fatty acids; PI: peroxidizability index

\begin{tabular}{|c|c|c|c|}
\hline & Tg sorbitol & $\mathrm{Tg} \mathrm{Fe}$ & $p$ values \\
\hline $14: 0$ & $0.7 \pm 0.1$ & $0.6 \pm 0.05$ & 0.60 \\
\hline $16: 0$ & $21.5 \pm 0.6$ & $25.4 \pm 1.2$ & 0.03 \\
\hline $16: 1 n-7$ & $0.5 \pm 0.07$ & $0.8 \pm 0.15$ & 0.14 \\
\hline $18: 0$ & $19.2 \pm 0.3$ & $21.0 \pm 0.7$ & 0.05 \\
\hline $18: 1 n-9$ & $18.2 \pm 0.4$ & $18.5 \pm 0.5$ & 0.63 \\
\hline $18: 2 n-6$ & $4.3 \pm 0.3$ & $3.0 \pm 0.2$ & 0.01 \\
\hline $18: 3 n-3$ & $0.1 \pm 0.02$ & $0.9 \pm 0.5$ & 0.15 \\
\hline $18: 4 n-6$ & $0.2 \pm 0.02$ & $0.2 \pm 0.03$ & 0.63 \\
\hline $20: 0$ & $0.3 \pm 0.02$ & $0.3 \pm 0.1$ & 0.618 \\
\hline $20: 1 n-9$ & $1.0 \pm 0.05$ & $1.1 \pm 0.07$ & 0.41 \\
\hline $20: 2 n-6$ & $0.3 \pm 0.02$ & $0.3 \pm 0.08$ & 0.44 \\
\hline $20: 3 n-6$ & $0.3 \pm 0.04$ & $0.3 \pm 0.03$ & 0.74 \\
\hline $20: 4 n-6$ & $7.3 \pm 0.5$ & $7.6 \pm 0.3$ & 0.56 \\
\hline $20: 5 n-3$ & $8.2 \pm 1.3$ & $4.8 \pm 1.3$ & 0.08 \\
\hline $22: 0$ & $1.2 \pm 0.1$ & $0.9 \pm 0.15$ & 0.16 \\
\hline $22: 4 n-6$ & $2.4 \pm 0.45$ & $2.0 \pm 0.04$ & 0.42 \\
\hline $22: 5 n-6$ & $0.5 \pm 0.1$ & $0.4 \pm 0.04$ & 0.68 \\
\hline $22: 5 n-3$ & $2.3 \pm 0.6$ & $0.7 \pm 0.1$ & 0.03 \\
\hline $24: 0$ & $0.7 \pm 0.1$ & $0.4 \pm 0.1$ & 0.05 \\
\hline $22: 6 n-3$ & $9.7 \pm 1.5$ & $9.9 \pm 0.3$ & 0.88 \\
\hline $24: 5 n-3$ & $0.5 \pm 0.08$ & $0.3 \pm 0.05$ & 0.10 \\
\hline $24: 6 n-3$ & $0.6 \pm 0.1$ & $0.4 \pm 0.02$ & 0.13 \\
\hline $\mathrm{ACL}$ & $18.6 \pm 0.04$ & $18.4 \pm 0.06$ & 0.01 \\
\hline SFA & $43.5 \pm 0.8$ & $48.7 \pm 1.3$ & 0.01 \\
\hline UFA & $56.5 \pm 0.8$ & $51.3 \pm 1.3$ & 0.01 \\
\hline MUFA & $19.8 \pm 0.3$ & $20.5 \pm 0.6$ & 0.33 \\
\hline PUFA & $36.7 \pm 0.7$ & $30.9 \pm 1.5$ & 0.01 \\
\hline PUFAn-3 & $21.4 \pm 0.6$ & $17.0 \pm 1.1$ & 0.01 \\
\hline PUFAn-6 & $15.3 \pm 0.7$ & $13.8 \pm 0.5$ & 0.14 \\
\hline DBI & $189.0 \pm 4.4$ & $163.2 \pm 6.9$ & 0.02 \\
\hline PI & $196.7 \pm 5.9$ & $165.7 \pm 8.7$ & 0.02 \\
\hline
\end{tabular}

Table 2

Markers of oxidative damage in frontal cortex in A $\beta$ PP/PS1 mice treated with iron $(\mathrm{TgFe})$ in vehicle or with sorbitol alone (Tg sorbitol) in neonatal period and killed at the age of six months. Values are means \pm SEM from $n=4$ samples. GSA: Glutamic semialdehyde; AASA: aminoadipic semialdehydes; CML: $\mathrm{N}^{{ }^{-}}$carboxymethyl-lysine; CEL: $\mathrm{N}^{\varepsilon}$-carboxyethyl-lysine; MDAL: $\mathrm{N}^{\varepsilon}$ malondialdehyde-lysine. Units: $\mu \mathrm{mol} / \mathrm{mol}$ lysine

\begin{tabular}{lccc}
\hline & Tg Sorbitol & Tg Fe & $p($ Tg vs. TgFe $)$ \\
\hline GSA & $6885.5 \pm 314.5$ & $5987.3 \pm 155.0$ & 0.03 \\
AASA & $86.9 \pm 3.6$ & $64.6 \pm 2.9$ & 0.001 \\
CEL & $270.2 \pm 10.4$ & $212.9 \pm 6.8$ & 0.002 \\
CML & $352.4 \pm 25.2$ & $233.1 \pm 14.4$ & 0.003 \\
MDAL & $1263.6 \pm 96.2$ & $938.0 \pm 29.3$ & 0.01 \\
\hline
\end{tabular}

Acute and chronic brain insults trigger a specific glial reaction, generally known as reactive astrogliosis, represented by a complex morphofunctional remodeling of astrocytes [12]. GFAP expression also increases with aging in the human brain; astrocytes may respond to preclinical AD molecular pathology [34]. In line with these observations in $\mathrm{AD}$, recent studies have shown that the number of astrocytes is significantly increased in the hippocampus in $\mathrm{A} \beta \mathrm{PP} / \mathrm{PS} 1$ mice compared with age- and gender-matched wild-type littermates [10]. Exactly the same results have been reproduced in the present study, thus indicating that astrocytic gliosis is an early event in the course of $\mathrm{A} \beta \mathrm{PP} / \mathrm{PS} 1$-related pathology. Additionally, and critically, iron administration during the neonatal period and later effects are independent of the genetic substrate of the individual, as similar astrocytic responses occur in $\mathrm{A} \beta \mathrm{PP} / \mathrm{PS} 1$ and wild-type littermates.

The brain is unique in its homeostatic management of iron in that saturation of iron-handling proteins can occur more rapidly in the brain than in the peripheral organs [20]. Iron accumulation and overload have been identified as a severe toxic event affecting brain cells. At certain iron concentrations, the defenses of brain cells may fail, and homeostatic mechanisms are overwhelmed. Under such conditions, differential cellular responses in brain-associated cell types are recruited to manage cell survival [20]. For instance, it has been demonstrated that astrocytes are more resistant to free iron toxicity than neurons and brain vascular endothelial cells, and may even provide transient protection to other cells within the brain [20]. A similar response may also occur at less toxic doses of iron, thus explaining astrocytic reactions in adult animals following neonatal administration of $10.0 \mathrm{mg} / \mathrm{Kg}$ of body weight of iron carbonyl in postnatal days 12, 13, and 14 .

Mechanisms leading to accompanying metabolic changes in the brain of adult mice treated with iron in the neonatal period are difficult to follow as a single point at the age of six months is available for study in $\mathrm{A} \beta \mathrm{PP} / \mathrm{PS} 1$ mice. Yet it can be assumed, as a working hypothesis, that iron treatment during the neonatal period may enhance Fenton-type reactions, leading to oxidative stress in this period. These reactions may be followed by net flux of free radical generation leading to protein modifications and membrane susceptibility to lipid peroxidation, as well as qualitative and quantitative changes in cell types. It has been demonstrated that oxidative effects due to in vivo exposure to iron involve not only Fenton reaction, but also complex mechanisms related to hormones release. Kokoszko et al. demonstrated that in brain GH decreased whereas IGF1 increased basal oxidative lipid peroxidation after iron injection in rats. In our experiment, $\mathrm{GH}$ would be a protector factor to early iron overload ingestion [35]. Con- 
cerning protein modifications, the percentage of change in the five measured markers of protein oxidative damage, resulting in reduced glutamic and aminoadipic semialdehydes, $\mathrm{N}^{\varepsilon}$-carboxymethyl-lysine, $\mathrm{N}^{\varepsilon}$ carboxyethyl-lysine and $\mathrm{N}^{\varepsilon}$-malondialdehyde-lysine, is compatible with a homeostatic response to onetime increased oxidative damage [36]. Similarly, the changes in fatty acid composition are clearly compatible with an adaptive response of brain to iron intake. Thus, the depletion of 20 and 22 carbon n-3 precursors would reflect an attempt to spare the levels of docosahexaenoic acid. The conserved docosahexaenoic levels, allowing for the essential functions of this fatty acid in neurons, seem to confirm a successful response. These changes in lipid composition lead to a lower lipid peroxidizability, a fact that would also contribute to reduced protein oxidative damage [37]. The results of fatty acid analyses and levels of protein oxidative damage are complementary, and, taken together, reflect an adaptation to increased oxidative damage geared to curve protein oxidative damage and lipid peroxidizability. It was previously demonstrated that iron administration in the postnatal period induces mitochondrial dysfunction in adult rats, with consequent increase in superoxide production, which was accompanied by an increase in SOD activity in cortex hippocampus and substantia nigra, but not in striatum [29]. Thus, further experiments aiming to investigate other possible alterations induced by neonatal iron treatment in oxidative parameters in transgenic mice are warranted.

Whether the changes found are specific to $\mathrm{A} \beta \mathrm{PP} / \mathrm{PS} 1$ transgenic mice is not known, but in all likelihood they are not. Studies in a limited number of wild-type littermates treated with iron or with sorbitol alone ( $n=$ 2 per group) showed a similar pattern as that observed in $\mathrm{A} \beta \mathrm{PP} / \mathrm{PS} 1$ mice (unpublished observations).

In summary, the present study shows that increased iron availability to the nervous tissue at early stages of development in A $\beta$ PP/PS1 mice results in significant cellular (increased astrocytes and increased GFAP expression levels) and metabolic (brain lipid composition, and reduced index of peroxidizability and oxidative protein damage) responses that are maintained later in life. Although these results suggest a permanent cellular and molecular defense to transient iron overload during development, it may be questioned whether these changes are protective or facilitators of later brain damage. The absence of increased microglial responses, the lack of increased amyloid burden, together with reduced index of lipid peroxidizability and oxidative protein damage in iron-treated mice, are indicators of a scenario consistent with reduced vulnerability to oxidative stress. Yet increased astrocytic gliosis usually reflects impaired neuronal/glial homeostasis [12,34,38]. It is well documented that perinatal iron deficiency is causative of brain damage persisting into adult life [3943]. The present findings clearly document that excess of iron during the neonatal period also impacts in the cellular and molecular composition of the adult brain. Furthermore, early Fe administration during development does not interfere with the appearance of amyloid plaques in $\mathrm{A} \beta \mathrm{PP} / \mathrm{PS} 1$ transgenic mice.

\section{ACKNOWLEDGMENTS}

LLF was a recipient of a CAPES/ MEC PDEE fellowship. Work carried out at the Institute of Neuropathology was partially funded by grants from the Spanish Ministry of Health, Instituto de Salud Carlos III PI080582. Work carried out at the Department of Experimental Medicine was supported in part by $\mathrm{R}+\mathrm{D}$ grants from the Spanish Ministry of Science and Innovation (AGL2006-12433 and BFU200911879/BFI), the Spanish Ministry of Health (ISCIII, Red de Envejecimiento y Fragilidad, RD06/0013/0012 and PI081843), the Autonomous Government of Catalonia (2009SGR735), 'La Caixa' Foundation, and COST B-35 Action. Alba Naudí received a predoctoral fellowship from 'La Caixa' Foundation. We wish to thank J. Visa, G. Muntané, and G. Santpere for animal treatment and care. Thanks to T. Yohannan for editorial help.

Authors' disclosures available online (http://www.jalz.com/disclosures/view.php?id=178).

\section{REFERENCES}

[1] Qiu C, Kivipelto M, von Strauss E (2009) Epidemiology of Alzheimer's disease: occurrence, determinants, and strategies toward intervention. Dialogues Clin Neurosci 11, 111-128.

[2] Bossy-Wetzel E, Schwarzenbacher R, Lipton SA (2004) Molecular pathways to neurodegenaration. Nat Med 10 (Suppl), S2-S9.

[3] Selkoe DJ (2004) Cell biology of protein misfolding: The examples of Alzheimer's and Parkinson's diseases. Nat Cell Biol 6, 1054-1061.

[4] Blennow K, De Leon MJ, Zetterberg H (2006) Alzheimer's disease. Lancet 368, 387-403.

[5] Bertram L, Tanzi RE (2005) The genetic epidemiology of neurodegenerative disease. J Clin Invest 115, 1449-1457.

[6] Fernandez LL, Scheibe RM (2005) Is MTHFR polymorphism a risk factor for Alzheimer's disease like APOE? Arq Neuropsiquiatr 63, 1-6. 
[7] Borchelt DR, Thinakaran G, Eckman CB, Lee MK, Davenport F, Ratovitsky T, Prada CM, Kim G, Seekins S, Yager D, Slunt HH, Wang R, Seeger M, Levey AI, Gandy SE, Copeland NG, Jenkins NA, Price DL, Younkin SG, Sisodia SS (1996) Familial Alzheimer's disease-linked Presenilin 1 variants elevate A 31-42/1-40 ratio in vitro and in vivo. Neuron 17, 1005-1013.

[8] Scheuner D, Eckman C, Jensen M, Song X, Citron M, Suzuki N, Bird TD, Hardy J, Hutton M, Kukull W, Larson E, Levy-Lahad E, Viitanen M, Peskind E, Poorkaj P, Schellenberg G, Tanzi R, Wasco W, Lannfelt L, Selkoe D, Younkin S (1996) Secreted amyloid beta-protein similar to that in the senile plaques of Alzheimer's disease is increased in vivo by the presenilin 1 and 2 and APP mutations linked to familial Alzheimer's disease. Nat Med 2, 864-870.

[9] McGowan E, Sanders S, Iwatsubo T, Takeuchi A, Saido T, Zehr C, Yu X, Uljon S, Wang R, Mann D, Dickson D, Duff K (1999) Amyloid phenotype characterization of transgenic mice overexpressing both mutant amyloid precursor protein and mutant presenilin 1 transgenes. Neurobiol Dis 6, 231-244.

[10] Manaye KF, Wang PC, O`Neil JN, Huang SY, Xu T, Lei DL (2007) Neuropathological quantification of dtg APP/PS1: neuroimaging, stereology, and biochemistry. Age 29, 87-96.

[11] Perez M, Moran MA, Ferrer I, Avila J, Gomez-Ramos P (2008) Phosphorylated tau in neuritic plaques of APPsw/tauvlw transgenic mice and Alzheimer disease. Acta Neuropathol 116, 409-418.

[12] Rodriguez JJ, Olabarria M, Cchvatal A, Verkhratsky A (2009) Astroglia in dementia and Alzheimer's disease. Cell Death Diff 16, 378-385.

[13] Knafo S, Alonso-Manclares L, Gonzalez-Soriano J, MerinoSerais P, Fernaud-Espinosa I, Ferrer I, DeFelipe J (2009) Widespread changes in dendritic spines in a model of Alzheimer disease. Cereb Cortex 19, 586-592.

[14] Egaña JT, Zambrano C, Nuñez MT, Gonzalez-Billault C, Maccioni RB (2003) Iron-induced oxidative stress modifies tau phosphorylation patterns in hippocampal cell cultures. Biometals 16, 215-223.

[15] Huang X, Atwood CS, Moir RD, Hartshorn MA, Tanzi RE, Bush AI (2004) Trace metal contamination initiates the apparent auto-aggregation, amyloidosis, and oligomerization. $J$ Biol Inorg Chem 9, 954-960.

[16] Riederer PF (2004) View on neurodegeneration as a basis for neuroprotective strategies. Med Sci Monit 10, RA287-290.

[17] Lee DW, Andersen JK, Kaur D (2006) Iron dysregulation and neurodegeneration: the molecular connection. Mol Interven 6, 89-97.

[18] Fernandez LL, Fornari LHT, Barbosa MV, Schroder N (2007) Iron and neurodegeneration. Scientia Medica 17, 218-224.

[19] Molina-Holgado F, Hider RC, Gaeta A, Williams R, Francis P (2007) Metal iron and neurodegeneration. Biometals 20, 639-654.

[20] Castellani RJ, Moreira PI, Liu G, Dobson J, Perry G, Smith MA, Zhu X (2007) Iron: The redox-active center of oxidative stress in Alzheimer disease. Neurochem Res 32, 1640-1645.

[21] Quintana C, Bellefqih S, Laval JY, Guerquin-Kern JL, Wu TD, Avila J, Ferrer I, Arranz R, Patiño C (2006) Study of the localization of iron, ferritin, and hemossiderin in Alzheimer's disease hippocampus by analytical microscopy at the subcellular level. J Struct Biol 153, 42-54.

[22] Gaasch JA, Lockman PR, Geldenhuys WJ, Allen DD, Van der Schyf CJ (2007) Brain iron toxicity: differential responses of astrocytes, neurons, and endothelial cells. Neurochem Res 32, 1196-1208.
[23] Falangola MF, Lee SP, Nixon RA, Duff K, Helpem JA (2005) Histological co-localization of iron in A $\beta$ plaques of PS/APP transgenic mice. Neurochem Res 30, 201-205.

[24] Fredriksson A, Schröder N, Eriksson P, Izquierdo I, Archer T (1999) Neonatal iron exposure induces neurobehavioral dysfunction in adult mice. Toxicol Appl Pharmacol 159, 25-30.

[25] Fredriksson A, Schröder n, Eriksson P, Izquierdo I, Archer T (2000) Maze learning and motor activity deficits in adult mice induced by iron exposure during a critical post natal period. Dev Brain Res 119, 65-74.

[26] Schröder N, Fredriksson A, Vianna MRM, Roesler R, Izquierdo I, Archer T (2001) Memory deficits in adult rats following post natal iron administration. Behav Brain Res 124, 77-85.

[27] de Lima MN, Presti-Torres J, Garcia VA, Guimarães MR, Scalco FS, Roesler R, Schröder N (2008) Amelioration of recognition memory impairment associated with iron loading or aging by the type 4-specific phosphodiesterase inhibitor rolipram in rats. Neuropharmacology $\mathbf{5 5}, \mathbf{7 8 8 - 7 9 2 . ~}$

[28] de Lima MNN, Presti-Torres J, Caldana F, Grazziotin MM, Scalco FS, Guimarães MR (2007) Desferoxamine reverses neonatal iron-induced recognition memory impairment in rats. Eur J Pharmacol 570, 111-114.

[29] de Lima MN, Polydoro M, Laranja DC, Bonatto F, Bromberg E, Moreira JC, Dal-Pizzol F, Schröder N (2005) Recognition memory impairment and brain oxidative stress by postnatal iron administration. Eur J Neurosci 21, 2521-2528.

[30] de Lima MN, Laranja DC, Caldana F, Grazziotin MM, Garcia VA, Dal-Pizzol F, Bromberg E, Schröder N (2005) Selegiline protects against recognition memory impairments induced by neonatal iron treatment. Exp Neurol 196, 177-183.

[31] Pamplona R, Dalfó E, Ayala V, Bellmunt MJ, Prat J, Ferrer I, Portero-Otín M (2005) Proteins in human brain cortex are modified by oxidation, glycoxidation, and lipoxidation. Effects of Alzheimer disease and identification of lipoxidation targets. J Biol Chem 280, 21522-21530.

[32] Kontush A (2004) Apolipoprotein A $\beta$ : Black sheep in a good family. Brain Pathol 14, 433-446.

[33] Bishop GM, Robinson SR (2004) The Amyloid paradox: Amyloid- $\beta$-metal complexes can be neurotoxic and neuroprotective. Brain Pathol 14, 448-452.

[34] Wharton SB, O'Callaghan JP, Savva GM, Nicoll JA, Matthews F, Simpson JE, Forster G, Shaw PJ, Brayne C, Ince PG; MRC Cognitive Function and Ageing Neuropathology Study Group (2009) Population variation in glial fibrillary acidic protein levels in brain ageing: relationship to Alzheimer-type pathology and dementia. Dement Geriatr Cogn Disord 27, 465-473.

[35] Kokoszko A, Dabrowski J, Lewinski A, Karbownik-Lewinska M (2008) Protective effects of GH and IGF-1 against ironinduced lipid peroxidation in vivo. Exp Toxicol Pathol 60, 453-458.

[36] Breusing N, Grune T (2008) Regulation of proteasomemediated protein degradation during oxidative stress and aging. Biol Chem 389, 203-209.

[37] Pamplona R (2008) Membrane phospholipids, lipoxidative damage and molecular integrity: a causal role in aging and longevity. Biochim Biophys Acta 1777, 1249-1262.

[38] Salmina AB (2009) Neuron-glia interactions as therapeutic targets in neurodegeneration. J Alzheimers Dis 16, 485-502.

[39] Wu LL, Zhang L, Shao J, Qin YF, Yang RW, Zhao ZY (2008) Effect of postnatal iron deficiency on myelination and associated behaviors in rat pups. Behav Brain Res 188, 263-270.

[40] Georgieff MK (2008) The role of iron in neuropdevelopment: fetal iron deficiency and the developing hippocampus. Biochem Soc Trans 36, 1267-1271. 
[41] Tran PV, Fretham SJ, Carlson ES, Georgieff MK (2009) Longterm reduction of hippocampal BDNF activity following fetalneonatal iron deficiency in adult rats. Pediatr Res 65, 493-498.

[42] Carlson ES, Tkac I, Magid R, O'Connor MB, Andrews NC, Schallert T, Gunshin H, Georgieff MK, Petryk A (2009) Iron is essential for neuron development and memory functions in mouse hippocampus. J Nutr 139, 672-679.

[43] Collard KJ (2009) Iron homeostasis in the neonate. Pediatrics 123, 1208-1216. 